\title{
Spontaneous cholecystocutaneous abscess
}

\author{
Mayank Jayant • Robin Kaushik • Ashok K. Attri
}

Published online: 14 September 2013

(C) Indian Society of Gastroenterology 2013

Spontaneous cholecystocutaneous abscess or fistula is an uncommon complication of acute cholecystitis. This entity, frequent in the nineteenth century, is now rare with only 20 reported cases in the last 50 years [1]. This 42-year-old female presented with upper abdominal pain, fever, chills, swelling, and discharge in upper abdomen. Examination revealed a ruptured abscess cavity in the right hypochondrium (Fig. 1). Ultrasonography showed inflamed gallbladder, with multiple stones, adherent to abdominal wall. The cholecystocutaneous abscess was drained (Fig. 2), antibiotics were started, and

Fig. 1 Ruptured abscess cavity in the right hypochondrium

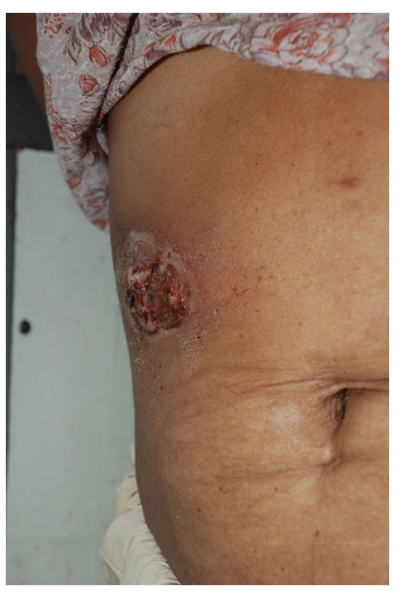

open cholecystectomy was done 5 days later. The condition is invariably a complication of neglected calculus disease [2]. Obstruction of cystic duct neck due to stone leads to inflammation, adherence of gallbladder to abdominal wall, parietal abscess, and eventually a fistula. Single-stage management in the form of cholecystectomy and debridement/drainage of abscess cavity along with antibiotic cover is the preferred approach. The declining incidence is likely due to early diagnosis, use of antibiotics, and prompt cholecystectomy [2].

\section{References}

1. Junior RJ, Nahas J, Figueiredo LF. Spontaneous cholecystocutaneous fistula: a rare complication of gallbladder disease. Sao Paulo Med J. 2006;124:234-6.

Department of Surgery, Government Medical College and Hospital, Sector 32, Chandigarh 160 047, India e-mail: mayankjayant@rediffmail.com
2. Metsemakers WJ, Quanten I, Vanhoenacker F, Spiessens T. Spontaneous cholecystocutaneous abscess. JBR-BTR. 2010;93:198-200. 